\title{
Contaminação de praças públicas de Campo Grande, Mato Grosso do Sul, Brasil, por ovos deToxocara eAncylostoma em fezes de cães
}

\author{
Contamination of public squares of Campo Grande, \\ Mato Grosso do Sul, Brazil, by eggs of Toxocara \\ and Ancylostoma in dog feces
}

\author{
Flábio Ribeiro de Araújo', Adalberto José Crocci², Ráucia Gleick Carneiro Rodrigues', \\ Janine da Silva Avalhaes', Michely Isis Miyoshi', Fabiana Pessoa Salgado', \\ Márcio Antônio da Silva' ${ }^{1}$ e Marcelo Lima Pereira ${ }^{1}$
}

Resumo De fevereiro a outubro de 1998, avaliou-se a contaminação de praças públicas de Campo Grande, MS, Brasil, por ovos de Toxocara e Ancylostoma, em amostras de fezes de cães. Das 74 praças examinadas, $42(56,8 \%)$ estavam contaminadas por ovos de Ancylostoma, $8(10,8 \%)$ com ovos de Toxocara e $7(9,5 \%)$ com ambos.

Palavras-chaves: Toxocara. Ancylostoma. Contaminação. Praças públicas. Fezes de cães.

Abstract From February to October 1998, the contamination of public squares of Campo Grande, MS, Brazil, by eggs of Toxocara and Ancylostoma was evaluated in dog fecal samples. Out of the 74 public parks examined, $42(56.8 \%)$ were found to be contaminated with Ancylostoma eggs, 8 (10.8\%) with Toxocara eggs and 7 (9.5\%) with both.

Key-words: Toxocara. Ancylostoma. Contamination. Public squares. Dog feces. ${ }^{1}$

A contaminação de praças pública por fezes de cães constitui um problema de Saúde Pública, devido à possibilidade de transmissão de zoonoses, especialmente a Larva migrans visceral (LMV) e a Larva migrans cutânea (LMC).

A LMV resulta da migração de larvas de helmintos, principalmente Toxocara canis ${ }^{2}$, através de órgãos como o pulmão e o fígado ${ }^{6}$. A infecção ocorre pela ingestão de ovos larvados de $T$. canis presentes no solo.

A LMC é causada pela migração de larvas de nematódeos pela pele de um hospedeiro não habitual. No Brasil, esta dermatose é causada principalmente pelas larvas de Ancylostoma braziliense e $A$. caninum, presentes em solos contaminados ${ }^{5}$.
Um estudo realizado em crianças atendidas na Divisão de Pediatria do Hospital Universitário de Campo Grande, MS, Brasil, selecionadas por uma alta contagem de eosinófilos, mostrou que $35,5 \%$ destas eram soropositivas para $T$. canis ${ }^{6}$. Estes dados sugerem que as praças públicas de Campo Grande podem estar contaminadas por ovos de helmintos de cães, uma vez que a maioria não possui cercas, permitindo o livre acesso de cães vadios.

No período de fevereiro a outubro de 1998, avaliou-se a contaminação de praças públicas de Campo Grande, MS, por ovos de Toxocara e Ancylostoma. Foram escolhidas aleatoriamente 74 praças das 99 existentes no município $(74,7 \%)$, distribuídas nas regiões oeste (17), leste

1. Centro de Ciências Biológicas, Agrárias e da Saúde, Universidade para o Desenvolvimento do Estado e da Região do Pantanal (UNIDERP). 2. Departamento de Bioestatística do Instituto de Biociências da UNESP, Campus de Botucatu, Botucatu, SP, Brasil. Endereço para correspondência: Dr. Flábio Ribeiro de Araújo. UNIDERP. R. Alexandre Herculano 1400, 79002-970 Campo Grande, MS, Brasil. Fax: 5567 726-3754.

Recebido para publicação em 23/12/98. 
(17), sul (17), norte (5) e centro (18). Amostras de fezes de cães foram coletadas em sacos plásticos no início da manhã e enviadas sob refrigeração e sem a adição de soluções conservantes, para o Laboratório de Parasitologia da UNIDERP. As amostras foram processadas no mesmo dia da coleta, através das técnicas de flutuação em solução saturada de açúcar e de sedimentação simples e examinadas para presença de ovos de Toxocarae Ancylostoma por microscopia. Para cada amostra de fezes foi examinada uma lâmina.

Das 74 praças examinadas, $8(10,8 \%)$ estavam contaminadas com ovos de Toxocara e $42(56,8 \%)$ com ovos de Ancylostoma. A distribuição das praças contaminadas por ovos de Toxocara e Ancylostoma por região está demonstrada na Tabela 1.

Tabela 1 - Contaminação de praças públicas por ovos de Toxocara e Ancylostoma em Campo Grande, MS, Brasil, de fevereiro a outubro de 1998.

\begin{tabular}{|c|c|c|c|c|c|c|c|}
\hline \multirow[t]{3}{*}{ Região } & \multirow{3}{*}{$\begin{array}{c}\text { Praças } \\
\text { examinadas } \\
\mathrm{n}^{\circ}\end{array}$} & \multicolumn{6}{|c|}{ Praças contaminadas } \\
\hline & & \multicolumn{2}{|c|}{ Ovos de Toxocara } & \multicolumn{2}{|c|}{ Ovos de Ancyostoma } & \multicolumn{2}{|c|}{ Ambos } \\
\hline & & $\mathrm{n}^{0}$ & $\%$ & $\mathrm{n}^{\circ} \mathrm{o}$ & $\%$ & $\mathrm{n}^{0}$ & $\%$ \\
\hline Oeste & 17 & 1 & 5,9 & 8 & 47,0 & 1 & 5,9 \\
\hline Leste & 17 & 0 & 0,0 & 12 & 70,6 & 0 & 0,0 \\
\hline Sul & 17 & 3 & 17,6 & 12 & 70,6 & 2 & 11,8 \\
\hline Norte & 5 & 2 & 40,0 & 4 & 80,0 & 2 & 40,0 \\
\hline Centro & 18 & 2 & 11,1 & 6 & 33,3 & 2 & 11,1 \\
\hline Total & 74 & 8 & 10,8 & 42 & 56,8 & 7 & 9,5 \\
\hline
\end{tabular}

Não foram verificadas diferenças significativas entre as proporções $(p>0,10)$ pelo teste de Goodman ${ }^{5}$.

Amostras de solo de 15 locais públicos de Londrina, PR, foram examinadas através da flutuação em dicromato de sódio e em sulfato de zinco a $33 \%$, tendo sido encontrado $9(60 \%)$ contaminadas por ovos de Toxocara ${ }^{3}$. Em Salvador, BA, foram examinadas amostras de fezes de cães e de solos, colhidas de 23 bairros, através da técnica de sedimentação simples, sendo observado um alto grau de contaminação por ovos de Toxocara (100\%), considerando-se os resultados obtidos na análise dos dois tipos de amostra ${ }^{1}$. Em Uberlândia, MG, 23,1\% dos parques públicos examinados estavam contaminados por ovos de Toxocara spp, utilizando a técnica de flutuação em solução saturada de cloreto de sódio e de sulfato de magnésio ${ }^{4}$. As diferenças encontradas nestes estudos podem ter ocorrido devido às diversas metodologias empregadas ou mesmo podem refletir as diferenças entre os números de cães vadios entre as localidades.

A maioria dos estudos sobre a contaminação de praças públicas por ovos de helmintos de cães no Brasil enfocou a prevalência de Toxocara, devido à grande relevância da LMV. No entanto, em um surto de LMC em crianças de uma creche privada em Belo Horizonte, MG, a fonte de infecção foi uma caixa de areia contaminada por larvas de Ancylostoma ${ }^{5}$. Desta forma, a transmissão desta zoonose também deve ser considerada em praças públicas contaminadas por fezes de cães, como foi observado em Campo Grande.

Apesar da alta prevalência de ovos de helmintos em praças públicas de Campo Grande, especialmente de Ancylostoma, estes dados devem ser considerados subestimados, já que cada praça só foi visitada uma vez e não foram examinadas amostras de solo. Isto poderia aumentar ainda mais as taxas de contaminação. Por outro lado, a análise de amostras de solo poderia tornar os resultados menos precisos em relação à identificação dos ovos, já que os mesmos poderiam se apresentar larvados, inférteis ou degenerados.

Este estudo demonstrou o risco potencial da transmissão de zoonoses causadas por helmintos de cães, especialmente a LMC, pela população exposta, reforçando a necessidade de implementar medidas efetivas de Saúde Pública, como o controle da população canina com acesso às praças públicas, através da apreensão de animais vadios e a construção de cercas ao redor das áreas de recreação, como caixas de areia, ou sua cobertura com lonas durante a noite ${ }^{7}$. 


\section{REFERÊNCIAS BIBLIOGRÁFICAS}

1. Alcântara N, Bavia E, Silva RM, Carvalho E. Environmental contamination by Toxocara sp eggs in public areas of Salvador, Bahia State, Brazil. Revista da Sociedade Brasileira de Medicina Tropical 22:187-190, 1989.

2. Barra LAC, Santos WF, Chieffi PP, Bedaque PP, Salles PSC, Capitão CG, Vianna S, Hanna R, Pedretti Júnior L. Larva migrans visceral: forma mista de apresentação em adulto. Aspectos clínicos e laboratoriais. Revista da Sociedade Brasileira de Medicina Tropical 29:373-376, 1996.

3. Chieffi PP, Müller EE. Prevalência de parasitismo por Toxocara canis em cães e presença de ovos de Toxocara sp. no solo de localidades públicas da zona urbana do município de Londrina, Estado do Paraná, Brasil. Revista de Saúde Pública 10: 367-372, 1976.

4. Costa-Cruz JM, Nunes RS, Buso AG. Presença de ovos de Toxocara spp. em praças públicas da cidade de
Uberlândia, Minas Gerais, Brasil. Revista do Instituto de Medicina Tropical de São Paulo 36: 39-42, 1994.

5. Lima WS, Camargo MCV, Guimarães MP. Surto de Larva migrans em uma creche de Belo Horizonte, Minas Gerais (Brasil). Revista do Instituto de Medicina Tropical de São Paulo 26: 122-124, 1984.

6. Matos MF, Militão DN, Brum MAR, Omais M, Quilião ME, Dorval ME, Pereira AC, Possi LA, Sauer L, Camargo ED, Tundisi RN. Presence of anti-Toxocara antibodies in children selected at Hospital Universitário, Campo Grande, MS, Brazil. Revista do Instituto de Medicina Tropical de São Paulo 39: 49-50, 1997.

7. Uga S, Kataoka N. Measures to control Toxocara egg contamination in sandpits of public parks. American Journal of Tropical Medicine and Hygiene 52: 21-24, 1995. 